\title{
Establishing production service system and information collaboration platform for mold and die products
}

\author{
George Q. Huang • T. Qu • R. Y. Zhong • Z. Li • \\ H. D. Yang $\cdot$ Y. F. Zhang $\cdot$ Q. X. Chen $\cdot$ P. Y. Jiang $\cdot$ \\ X. Chen
}

Received: 12 May 2009 / Accepted: 4 January 2010/Published online: 9 June 2010

(C) The Author(s) 2010. This article is published with open access at Springerlink.com

\begin{abstract}
This paper investigates how the new concept of product service systems can be used and extended to transform, elevate, and revitalize traditional equipment manufacturing industry such as the Mold and Die (MD) sector. A mold and die production service systems (MPSS) framework is established based on recent developments within our industrial collaborators. Within the MPSS framework, MD manufacturers become more specialized in producing MD products and components while sharing and outsourcing manufacturing-oriented services (MOS) from a service provider. Typical services include collaborative order pooling and release, collaborative project progress status tracking, contractor-managed collaborative outsourcing, collaborative product design, collaborative production planning and scheduling, and after-sales technical supports. MOSs are designed, developed, and deployed as SaaS (software as application services) following the service-oriented architecture. Collectively, they form
\end{abstract}

G. Q. Huang $(\bowtie) \cdot$ T. Qu $\cdot$ R. Y. Zhong $\cdot$ Z. Li $\cdot$ Y. F. Zhang

Department of Industrial and Manufacturing Systems

Engineering, The University of Hong Kong,

Pokfulam, People's Republic of China

e-mail: gqhuang@hku.hk

P. Y. Jiang

College of Mechanical Engineering, Xi'an Jiao Tong University,

Xi'an, People's Republic of China

H. D. Yang

Department of Automation,

South China University of Science and Technology,

Guangzhou, People's Republic of China

Q. X. Chen $\cdot$ X. Chen

Department of Electromechanical Engineering,

Guangdong University of Technology,

Guangzhou, People's Republic of China
iMPSS - an Information and Collaboration Platform that enables MPSS. The use of iMPSS leads to benefits for stakeholders involved in providing mold and die functionality including better shopfloor decisions and reduced IT investments.

Keywords Product service system (PSS) · Service-oriented manufacturing $\cdot$ Manufacturing-oriented services $\cdot$ Mold and die Collaboration platform $\cdot$ Service-oriented architecture (SOA)

\section{Introduction}

The concept of product service system (PSS) is a recent innovation of business models for manufacturers to integrate their products and services to form and provide total solutions [3]. The adoption of PSS leads to significant changes in the way of doing businesses in a value chain. The revenue of a product manufacturer may come from the sale of providing product functionality while retaining the product ownership rather than from the sale of products. The roles of stakeholders in a PSS are different from those in a traditional manufacturing business model in the sense that stakeholders focus on providing the relevant services at different product lifecycle stages. For example, early efforts in PSS have emphasized on the sustainability of providing the product functionality from component production through material supplies to product recycling and disposal [29].

One of the most successful real-life examples of integrating services into products is that office users are renting, instead of buying, photocopiers. The rental is charged on the utilization level (e.g., number of copies). Users are ensured to enjoy the photocopying functionality 
during office hours through a pledge of timely repairing and maintenance services from a service stakeholder in this PSS. As another example, Rolls-Royce delivers "power-bythe-hour" instead of transferring ownership of the gas turbine engines to the airline companies [3]. To the end of consumer products, an example of integrating products into services is that mobile communication providers give a free handset of mobile phone to customers who sign-up for the service. Another example is that Internet Service Providers deploy Internet connection facilities in hotels free of charge but share the revenue obtained from residents' Internet connection services.

In between the above two ends of industrial and consumer products, there is a spectrum of PSS variations. Different product sectors may evolve to adopt and adapt to yet new PSS variations to best fit with their special characteristics. Cook and Bhamra [6] analyzed the applications and the shift of PSS from academia to industry. Williams [36] applied PSS in automotive industry and put forward the concept of micro-factory retailing. Mont [22] used the PSS as an approach for the manufacturing and sale of baby carriages. Sundin [31] used PSS to facilitate the recycling and reuse of components of soil compactors for Swepec in order to decrease maintenance cost as well as the impacts on environment. Evan and Partidario [7] investigated key factors of industrializing PSS applications in food production from three aspects as environment, economics, and society.

The concept of PSS has its particular attraction under the current economic crisis. The global market conditions and operating factors for manufacturing industries have recently changed dramatically. This is particularly obvious at the socalled "Factory of the World"-Pearl River Delta (PRD) region in Guangdong Province of southern China. These manufacturing companies have been affected by turbulent prices of crude oils and a wide variety of raw materials. The import and export tariffs have been also reformed in the nation. Labor costs have increased along with improved labor skills and the introduction of new labor laws. The exchange rate has appreciated significantly. These changes have significantly narrowed the profit margin to an extent that manufacturers are contemplating the possibility of moving their manufacturing facilities out of the region to where operating conditions are more favorable. Indeed, tens of thousands of plants have terminated their operations already in the region. This trend is unlikely to stop before the global and domestic economies recover if they do not make any changes in their business models. On the one hand, the shrinking global consumer market has led to the significant reduction of demands for industrial products such as molds and dies. On the other hand, the mold and die manufacturing industry must move a step ahead to become ready for economy recovery.
The aim of this research is to investigate how the PSS concept can be used and extended to transform, elevate, and revitalize the export-oriented manufacturing industry in the PRD region. The PRD mold and die (MD) manufacturing industry is used as an example for several reasons. Firstly, MD manufacturing industry is a very specialized and focused foundation industry for consumer product manufacturing industries. MD industry must become ready for forthcoming economic recovery. Secondly, MD manufacturing industry in the PRD region involves substantial foreign investments and accounts for almost half of the national MD output (http://www.gd.xinhuanet.com/). Thirdly, MD manufacturing processes are complicated and dynamic, involving sophisticated services among business units, either internal or external. MD manufacturers share significant common core technologies and services. Fourthly, the level of information technology (IT) usage is relatively high due to their complex engineering and shopfloor operations, especially with computer-aided design and manufacturing (CAD/CAM). Finally, noticeable developments have taken place along the line of PSS within leading mold and die manufacturers in the region. A new service-oriented value chain is emerging between MD users, manufacturers, and materials/component contractors/suppliers.

The study is primarily concerned with several research questions. The first question is why MD manufacturing industry needs to innovate its business model and what special characteristics must be addressed. The second question is what key components constitute a strategic PSS framework specific to the MD manufacturing industry. The third question is what services are most wanted by MD manufacturers throughout the key stages of the MD product lifecycle. The last question is how production-related services should be designed, developed, and deployed as software to form an information and collaboration platform.

The remainder of this paper is organized as follows. Section 2 sets out an innovative framework for mold and die product service system (MPSS) and how it works generally. Section 3 presents the architecture for iMPSSan information and collaboration platform that enables MPSS, together with typical services.

\section{Literature review}

The concept and practice of PSS have existed for a decade or so. During this period, PSS had achieved theoretical breakthrough with a variety of industrial cases. Researchers at Innovative Manufacturing Research Centre of Cranfield University [3] present a comprehensive state-of-the-art in PSS from various aspects, including definitions of a PSS, evolution of the concept, features of a PSS, applications, 
benefits, barriers to adoption, features in the effective design of a PSS, tools and methodologies for designing a PSS, and future research directions, and pointed out a highlighted finding in every aspect. Mont [20] also discusses the concept of PSS and its benefits, as well as the procedure and barriers of applying PSS. Interested readers should consult these review papers. This section highlights key developments in PSS.

Early efforts focused on sustainable product developments with relatively simple application cases such as car sharing $[5,27,30]$ and washing service $[34,35]$. Several major projects were funded in EU, for example SusProNet (http://www.suspronet.org/), MePSS (www.mepss.nl), and INNOPSE (http://upec2011.org/startmain.htm). These early projects have provided a good environment for PSS developments in the subsequent 5 years. More case studies and fundamental research works have been reported. For example, Manzini and Vezzoli [17] illustrate how PSS better satisfies essential requirements by shifting from the sale of products to sale of product-services. They also discuss in detail the potentials of optimizing resource utilization when implementing value-added services of PSS and improving enterprise strategy of sustainable development. Besch [4] investigate the application of PSS to furniture industry and proposes an approach to optimize its performance according to the sharing and remanufacturing of furniture products. After analyzing the bicycle-sharing cases, Luiten [15] formulate a five-step approach to help the company to achieve its PSS strategy. Taking the design of telecenter as an example, Morelli [23] demonstrate a perspective shift from focusing on material products to integrating products and services into systems. Correspondent methods and operational tools are also presented for developing a PSS.

The need for a systematic and more scientific framework for configuring and implementing PSS has been recognized. Scholars have attempted to develop quantitative models. For example, Komoto [13] proposes a product lifecycle simulation method to quantitatively analyze PSS from the perspective of economics and environment. Morelli [24] create a new pattern/methodology to develop PSS. Aurich et al. [1, 2] integrate the concepts of PLM and PSS (PSS-PLM) and propose a framework of PSS-PLM. Inside this framework, lifecycle activities can be systematically considered in an integrative manner. Lee [14] proposes an integrated manufacturing framework for the production and recycling of electronic products.

Recent interests in PSS have extended to industrial products. For example, Meier and Krug [19] and Aurich et al. [1, 2] put forward the concept of iPSS-PSS for industrial products. This emerges as a new turning point for further academic research and industrial applications. Meier and Krug [19] point out the disadvantages of machine services resulted from not-aligned product and service, and proposed a solution named industrial product service system which aims at integrating the development and supply of product and service. Evans et al. [7] assess the environmental, economic, and social performances of PSSs through three cases studies, proposed that sustainability benefits are achievable through using platforms and partners to design the PSSs. The research by Evans provides an effective direction to achieve an industrial product service solution. Aurich et al. [1,2] present iPSSs which are made up of a complex physical product core that is dynamically enhanced mainly with non-physical services along its life cycle. They use a case of road milling machine services to demonstrate how the lifecycle management of iPSS provides a promising starting point to exploit products' potentials.

Industrial products are often parts of a production system themselves. This leads to the integration of the PSS concept into a production system to become service-oriented manufacturing (SOM). As a result, iPSS becomes manufacturing-oriented services (MOS). This is particularly relevant to MD manufacturing industry based on recent investigations in our industrial collaborators. In this paper, we have used "Production" instead of "Product" in PSS, i.e., production service system. We have also extended the scope of MOSs to include shopfloor and enterprise production management services. The provision and consumption of these services often rely on enterprise information systems (EISs). This has not been adequately discussed in the context of PSS.

One key issue in PSS is the proportional contents of products and services configured in a PSS. The work on this issue has led to various PSS categorization schemes. Manzini [16] categorizes PSS into two modes, i.e., useoriented and result-oriented modes. Roy [29] further extends the categories to include four modes, i.e., result services, shared utilization services, product-life extension services, and demand side management. Recently, a threemode categorization becomes widely accepted. They include product-oriented, use-oriented, and result-oriented modes, in addition the traditional mode of buying and selling products. Baines et al. [3] has examined these variations of the PSS concept using the well-known photocopier example.

No matter which mode of PSS is practiced, benefits have been clear, from both existing successful cases $[6,8,26$, 36] and from theoretical analyses [25]; [3]. For customers, PSS not only ensures the acquirement of improved product functions (customized with higher quality), but also enables their releasing from the responsibilities of asset ownership and thus cut down the costs [6]. Moreover, innovative forms of value are suggested as being possible from most reported PSS cases [18, 28]. 
For manufacturers, PSS means an offering of higher value that is more easily differentiated. Firstly, strategic market opportunities could be offered through standardization and mass production. Secondly, total value for the customer could be improved through increasing service elements explored across the whole product lifecycle. Thirdly, production cost could be potentially reduced through delivering same or similar value-in-use.

For the whole society, PSS provides a sustainable approach not only to business, but also to the environmental protection. On the one hand, service sharing or reuse promoted by PSS largely reduces the resource use and waste generated [33]. On the other hand, manufacturers become more responsible for the produced products through take-back, recycling, and refurbishment [20]. Therefore, total production costs could be significantly reduced while causing less pressure to environment at the same time [21].

\section{Framework for mold and die production service system}

MDs are fundamental and indispensable tools for manufacturing industries. About $60-80 \%$ of parts and components in electronics, automobile, electrical, mechatronics, household appliance, telecommunication, and instrument products are formed with MDs. MDs create values that are many dozens or hundreds times of their own costs. In this sense, they are a value and productivity magnifier. Mold and die manufacturing (MDM) has direct impacts on product quality, productivity and innovation, raw material consumption, cost, and ultimately, the overall competitiveness.

\subsection{Information services in mold and die production}

The research reported in this paper has been motivated by our initial investigation into the concept and potential of PSS within collaborating MDM companies. Due to the rapid business growth and substantially evolved markets, these MDMs have to enhance their competitiveness through an enterprise "transform and upgrade" strategy.

Several preliminary findings are worth mentioning here. Firstly, MDM companies do not seem to be ready to consider and introduce any of the four typical PSS models [29] at this stage, although participating companies consider worthwhile to investigate the "Power-by-Hours" or photocopier PSS models for mold and die products.

The second finding is the emergence of a company that is specialized in providing production-related services to specialized MD manufacturers while MD manufacturers become more specialized in producing certain types of MD products and components while sharing and outsourcing production-related services from the MD service provider. The MOS provider (MOSP) and specialized MD manufacturers together form a new service-oriented MD manufacturing ecology which, in this research, is described as MPSS where P stands for production instead of product.

The third group of finding is that molds and dies are one-of-a-kind production (OKP) products. One set of product is typically ordered and manufacturing in nonrepetitive. Modularity and standardization are not commonly incorporated into mold and die designs. Key components are unique and little interchangeability is possible. Production planning and scheduling systems developed for repetitive manufacturing are not applicable. Many manufacturing operations do not have fixed times due to complex geometric shapes, with $\pm 30 \%$ deviation. Such uncertainty cannot be compensated among components which are unique.

Finally, mold and die production is highly resource intensive. The production of key components often involves operations that require specialized machines and therefore have to be outsourced. The host manufacturer and outsourced partners must exchange information about their capacity, capability, and loading in order to establish the best partnership. They also need to exchange information about the progress and status of the outsourced operations and components in order to synchronize their production plans and schedules.

Based on the above observations, our industrial collaborators indicated the need for an information service platform along the mold and die manufacturing value chain so that better manufacturing services are provided through enhanced the flow of information and information sharing among key stakeholders.

\subsection{Stakeholders in MPSS}

Figure 1 shows an overview of the strategic MPSS framework which includes key stakeholders, service components, and a general value chain. The following key stakeholders are involved in MPSS:

- Customers who use molds and dies to produce their product components (MD users).

- Alliance of SOMs for molds and dies (MD alliance).

- Manufacturers of final MD products that are assembled from components (MD lead manufacturer or MD leader). A lead MD manufacturer may also produce some key components in assembling the final MD products while other components may be outsourced.

- Contract manufacturers and suppliers of MD components and raw materials (MD contractors). 
- A company that provides manufacturing-oriented services to other stakeholders (MD MOSP)

It is important to point out that multiple SOMs of MD products are involved in the MD Alliance under the MPSS framework. This is different from the traditional business model where a MD manufacturer maintains its own customer and supply base. Individual SOMs have their specialized manufacturing capabilities and capacities that serve the customer requirements. Individual SOMs do not invest in developing MOSs while sharing them from MOSP. A group of MD manufacturers form an alliance within which they compete and collaborate with each other to work out the best strategy for fulfilling customer orders, optimizing the use of internal resources, and procuring/ outsourcing external resources. Such competing and collaborating partnership is also enabled by MOSP.

MOSP is specialized in providing MOSs along the whole lifecycle of the MD products from market research, order processing, production planning and scheduling, procurement and outsourcing, after-sales technical supports, and upgrading and reuse. Such services are packaged as software systems based on service-oriented architecture. MD manufacturers are upgraded by being able to share the MOS. They are transformed to better serve the domestic demands in the sense that the MOSP has the proximity to deal with domestic customer requirements while retaining superior responses to overseas markets.

\section{3 iMPSS: information and collaboration platform for MPSS}

Figure 2 shows an overview of a collaboration and information platform for MPSS, noted as iMPSS in short.
iMPSS is the technological engine of the MOSP which itself a relatively independent business entity in an MPSS framework. Five core service categories are implemented as software tools (SaaS), including MPSS configuration service tool, outsourcing service tool, collaborative DFX service tool, collaborative project tracking service tool and MPSS information center.

The first four service tools as shown at the upper part of the figure are application services. They are related to four phases in the MD product lifecycle, i.e., product configuration, supplier selection, collaborative product design, and product manufacturing. The corresponding MOS provided by these service tools are therefore PSS configuration, part outsourcing, collaborative DFX, and collaborative project tracking. These services tools could not only be used independently following the application service provision mode, but also be integrated into a complete collaborative MD product development process. Application services will be discussed in more detail in the next section.

The fifth service tool at the lower part of Fig. 2 is a centralized information service center. This MPSS-IC provides information sharing services for both application services and data source services. It is implemented as a Web service which is shared by source services at the bottom of the figure and by the application services at the upper level. This Web service provides a number of unified methods for different application services to obtain corresponding application data from heterogeneous sources or services including different types of databases (e.g., SQL Server, Oracle) and enterprise information systems (e.g., SAP, WMS, and MES). This MPSS-IC web service maintains and serves as an intermediate data repository for the entire MPSS platform. It also maintains a set of standard data models specific to application services. Data
Fig. 1 Mold and die manufacturing product service system (MPSS)

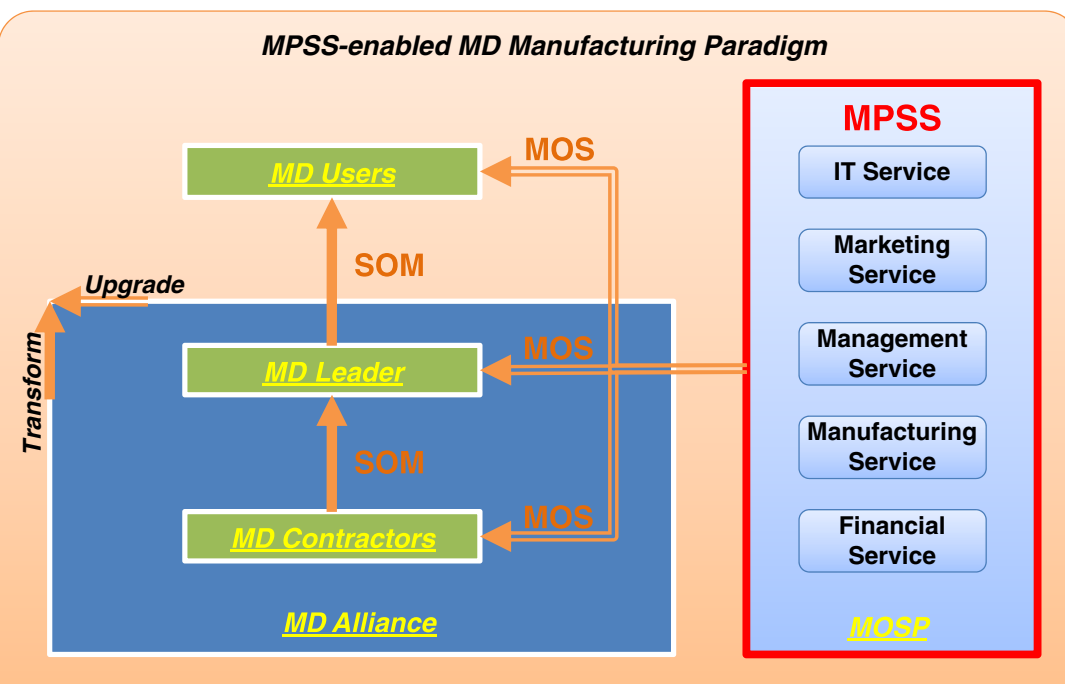

-MOS: Manufacturing-oriented Services SOM: Service-oriented Manufacturing 
Fig. 2 Architecture of iMPSS

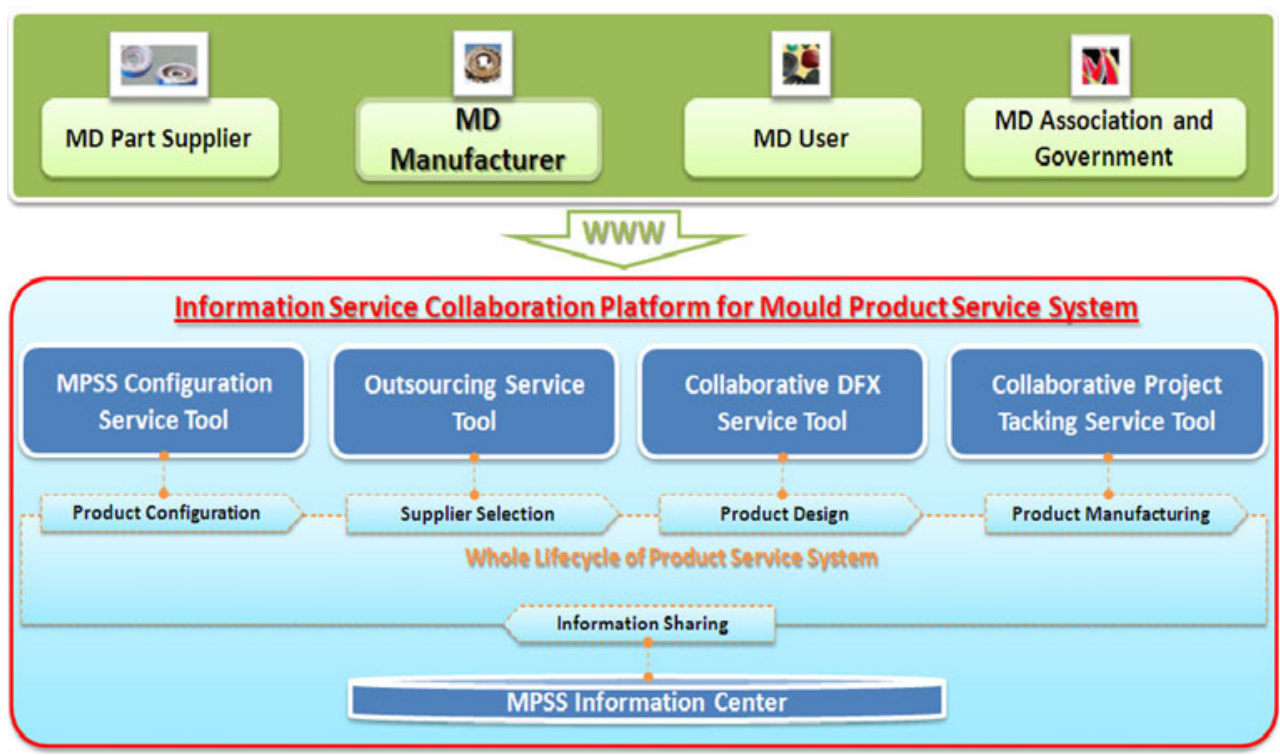

format are transformed through different parameters in the arguments of the Web service methods. Therefore, this MPSS-IC service plays an essential role in plug-and-play modular scalability of adding or removing application and/ or source services at the both ends.

\subsection{General procedure}

The general working procedure of the iMPSS framework includes three key stages. A customer initiates an MD order using the corresponding order-taking service provided by the MOSP instead of directly with an MD manufacturer. All customer orders are pooled within a given period of time. The MOSP analyzes and releases customer orders in the pool through the order release service. This service is based on a negotiation mechanism and governed by rules agreed by MPSS stakeholders. With this mechanism, members in the MD Alliance bid for projects to fulfill customer orders by matching their capabilities and capacities with order requirements. The winning $\mathrm{MD}$ manufacturer (member) becomes the project leader for a customer order. A projectspecific partnership is gradually and dynamically formed with outside contractors after evaluating their internal capabilities and capacities.

Once a customer order is released to an MD manufacturer as the project leader through the negotiation mechanism, a service relationship is established between the customer and the project leader. This top-level service of fulfilling the order is further decomposed into snippets according to the MD bill of materials (BOM) structure. Some snippets are completed internally, and some are outsourced through employing appropriate collaborative outsourcing services. As such, a service chain is established among MD manufacturers at different levels of the project hierarchy. Each MD manufacturer in this service hierarchy has its specialized capability which the other manufacturers are short of at a specific moment.

After the MD alliance starts the collaborative production process, the project leader will timely track the project progress and the real-time task fulfillment status through employing Kanban services. Customer order Kanban service is used when customers and project leaders want to know the overall progress of the project. Besides a calculated completion percentage, the overall progress could be further expanded to reveal two incorporated progresses of internal and external (outsourcing) tasks by production Kanban service and outsourcing Kanban service, respectively. In case problems occur in a manufacturing process, the project leader will be warned by corresponding Kanbans so as to immediately coordinate the affected partners to adjust the collaborative production plans to avoid project delay as much as possible.

When MD products come to use stage, after-sales services will be provided for customers by specialized companies in the MPSS framework. The use and condition of MD products could be closely monitored and recorded. Through real-time analysis of a decision support system, appropriate technical supports, and maintenance will be provided to customers for better using the MD products. After a MD product comes into disposal stage, its configuration file stored in iMPSS will be retrieved to generate a reuse and upgrading plan with all the MD manufacturers who have been part of the alliance for manufacturing this MD product.

\subsection{Manufacturing execution services in iMPSS}

This section presents typical MOSs as an example perceived in our collaborating companies. MOSs can be grouped into three categories according to the three key 
phases: product development, production, and after-sale. Typical collaborative product development services include collaborative "DFX-Design for X" (Huang and Mak, 1999), FMEA-Failure Mode and Effect Analysis [12], QFD-Quality Function Deployment [11], and Collaborative Design Review [9]. After-sale services include those services related to technical supports, maintenance, and recycling [32].

Based on the scope and focus of the joint research project, this section only discusses services related to shopfloor manufacturing execution being developed and deployed at iMPSS based on current and previous developments within the research group and collaborating companies.

\subsection{Collaborative order progress Kanban services}

Three levels of orders are important to shopfloor execution. They are customer orders, production orders, and outsourcing/purchase orders. Because MD products are generally OKP, each order is treated as a project. Therefore, customer orders and projects are used interchangeably. Customers, project managers, production managers, and shopfloor supervisors are interested in tracking the progress of these order projects. Tracking is complicated because these orders are related to each other from one level down to another iteratively. The concept of order progress Kanbans (OPK), a type of visibility explorers being developed in our research program, is developed.

The basic mechanism of OPK is a set of interrelated Gantt charts. Gantt charts are implemented using AJAX facilities. Standard XML documents are proposed and used to define and describe orders as inputs which are then rendered in web browsers. Order XML documents are compiled from various EISs, mainly from enterprise resource planning system.

The design of OPK services follows a top-down "pull" logic, as shown in Fig. 3. That is, the top-level service is for listing all customer orders that an MD manufacturer has been working on in an overall project Gantt chart. The detail of an individual order project can be drilled down or pulled out by double clicking on the corresponding item in the overall OPK Gantt chart. An order-level Gantt chart is then displayed, shown in the lower part of Fig. 3. This order Gantt chart is indented according to the BOM structure of the mold product. As BOM items are divided into two groups: make and buy. "Make" items are represented by production orders released to the shopfloor. "Buy" items are represented by outsourcing (including purchasing) orders released to external contractors.

The access to the level of details in this BOM hierarchy depends on the level of access authorities assigned to different users. For example, a project manager is able to drill-down from the top to the bottom levels of the order Kanban he or she is responsible. The memberships of external customers are classified into grades which also define the level of access to the BOM structure. For example, grade 0 customers can only see their orders as single items in the Gantt charts. Grade 1 customers are able to see the progress of items at level 1 in the BOM hierarchy and so on.

In addition to displaying the progresses, OPK services act as coordination mechanisms in manufacturing execution. The project order Kanban service can be used to support order and project reviews conducted regularly within our collaborating companies at the high level of project/order managers coordinated by a vice president. Outsourcing order Kanban service can be used to coordinate the delivery of outsourced components and/or operations. Work order Kanban service play an important role in coordinating production planning and scheduling for different components used in the same MD product and between MD products.

The order progress kanban concept can be used in a bilevel production planning and scheduling model. The Kanban mechanism provides a basis for analyzing the activity and project tolerances in line with the actual progress, current status, and expected delivery time. If the tolerance range exceeds certain limit, a warning signal is broadcast to all project partners to adjust their plan and schedules. If a delay occurs at an activity, affected activities are identified and alternative solution is generated within the given constraints. If no alternative solution exists, the project delay is estimated, and the customer is contacted to negotiate a new delivery date.

\subsection{Shopfloor asset status Kanban services}

In a broad sense, shopfloor assets can be grouped into three main categories: men, machines and materials. Asset status Kanban (ASK) services are for exploring the visibility of shopfloor facilities from viewpoints of various job functions. ASK services are similar to OPK services in the sense that the contents of information displayed are more or less the same, but the formats of presentation are different. While an OPK service shows the progress of a job at a machine by an operator using certain materials, an ASK service shows what jobs works are undertaken by a particular asset during a particular time period.

The design and implementation of ASK services, especially for men and machines, are also similar to those of OPK services. They are also based on Gantt charts. Figure 4 shows a typical ASK service for machines or machining centers. Once materials are requested and released from storerooms to the shopfloor, they become work-in-progress items which are usually contained in trays (a type of assets whose locations may change). Work-in- 
Fig. 3 Collaborative order progress Kanban services

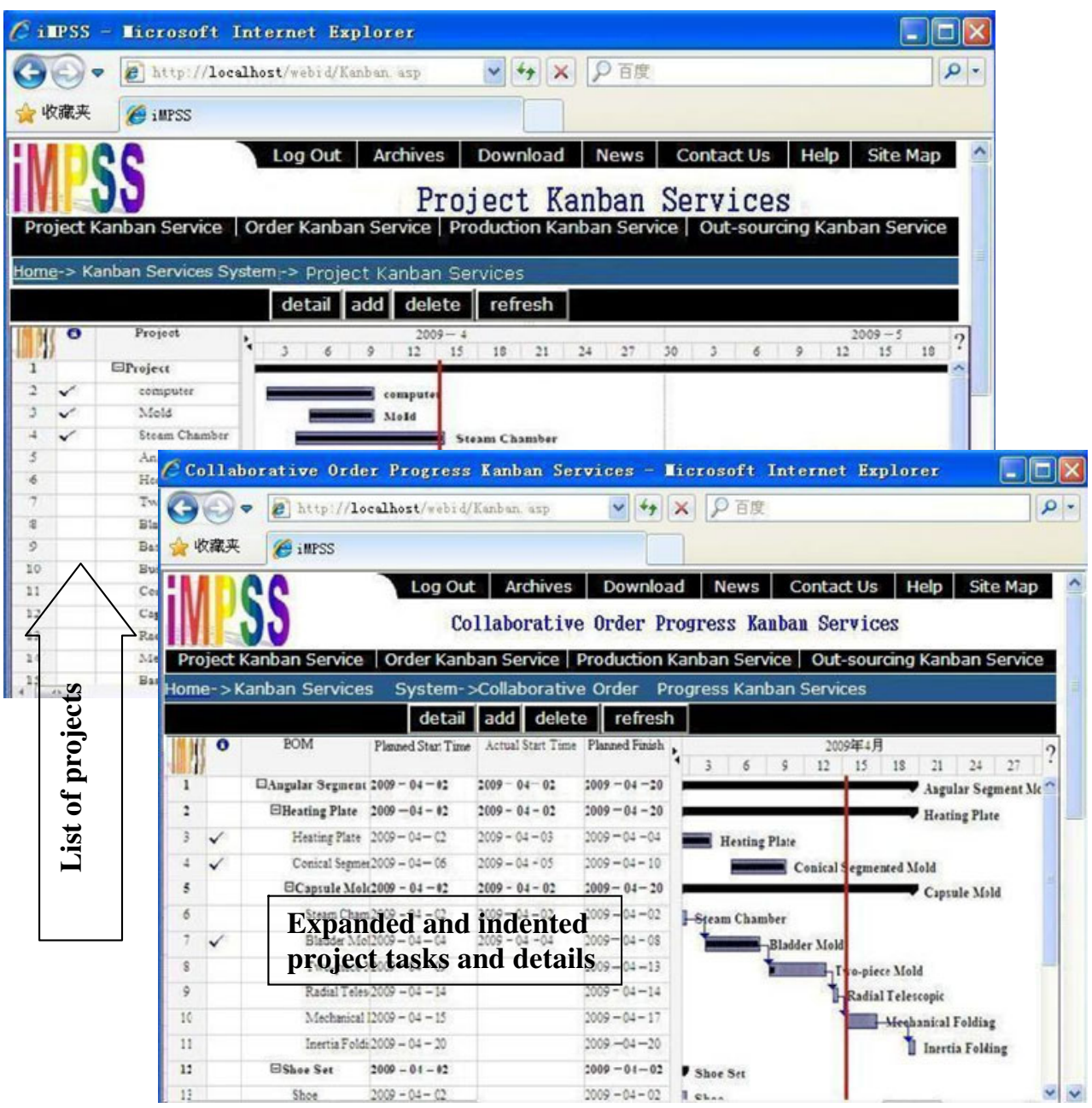

progress Kanban services provide facilities for their tracking and tracing.

Low-level assets are usually grouped to form high-level assets which are usually called shopfloor workstations or work cells. Work cells form a production line. Therefore, we will have work-cell status Kanban (WSK) or explorer and production line status Kanban (LSK) or explorers. LSK and WSK services provide multiple viewpoints of assets and orders (jobs) involved in the line and workstations.

ASK can be used in several ways. They provide visual facilities for operators and supervisors to better manage their operations onsite. Besides, they provide real-time data for shopfloor decision services such as capacity planning and scheduling. Finally, they can be used to evaluate asset performance. For example, the utilization rate or idle times can be evaluated for machines and operators using their status Kanbans.

\subsection{Contractor-managed outsourcing services}

Outsourcing is common in MD manufacturing industry due to requirements for specialized capability and/or capacity.
Some or all operations of components or modules can be outsourced from outside contractors and suppliers. Contractor-managed outsourcing (CMO) is a similar concept to vendor-managed inventory in supply chain management. In a CMO system, MD manufacturers' outsourcing inventories are managed by outside contractors. CMO services allow the MD manufacturer to announce its outsourcing requests among the alliance members. Interested contractors submit their bids for the announced outsourcing order. All bids are evaluated, and the best contractor is selected for the outsourcing order. The winning contractor picks up and returns the outsourcing job within the time window as promised in the bid.

The design and implementation of CMO services are based on our previous work on the WeBid system [10]. Figure 5 shows typical working sessions of CMO services. Outsourcing requirement service and contractor capability service is a pair of services used by the lead manufacturer and contractors, respectively. The lead manufacturer (project leader) invites bid by publishing its outsourcing requirements with the former, while each of the capable suppliers submit a bid reflecting its capabilities with the latter. Publishing bid 
Fig. 4 Shopfloor asset status

Kanban services at iMPSS

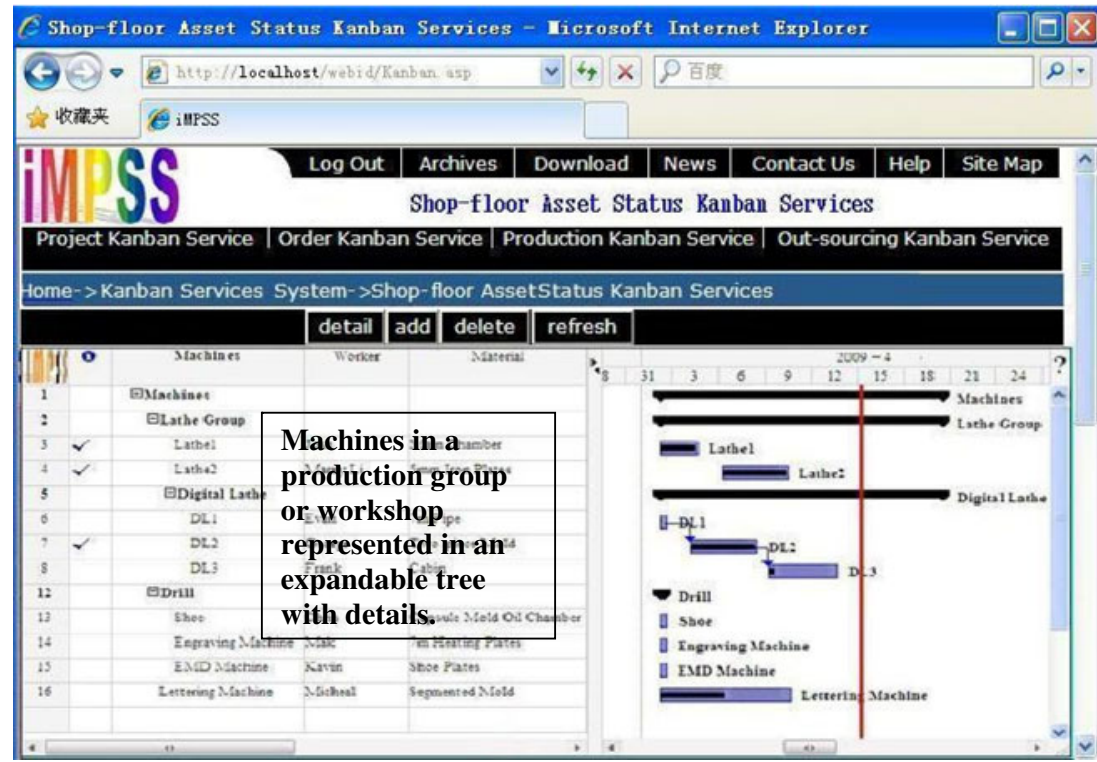

modifies and extends leader's requirements to represent design specifications. The items included in the bid/contract model are also called inquiry items or inquiries. Once suppliers have agreed upon the general items (inquiries) with the leader, they may start define their requirements and capabilities with the two services quantitatively, respectively. For each inquiry in the bid model, the value or value range is specified using the facilities provided in this tool. The process repeats until all the inquiries are considered.

The outsourcing partnership service is used by a project leader to select suitable supplier(s) from all the potentials through evaluating their capabilities in terms of four types of indices. Satisfaction index is the measure of extent to which a MD manufacturer's requirement is satisfied by a supplier's capability; flexibility index is the measure of extent to which a supplier's capability exceeds a MD manufacturer's requirement; risk index is the measure of extent to which a supplier capability fails to meet a MD manufacturer's requirement; confidence index is the measure of trustworthiness of the supplier meeting the MD manufacturer requirements over a period of specified time. The bidding party or parties with the most promising indices are considered further for awarding the contract.

\subsection{Production planning and scheduling services}

As MD manufacturing is typically OKP, its planning and scheduling models have unique requirements and features. SOMs share these functions of provided centrally at iMPSS. Figure 6 shows three levels of PPS services: releasing customer orders from the alliance to individual
MD manufacturer, releasing production orders by an individual MD manufacturer to its shopfloor, and scheduling the production work orders at the shopfloor in medium and short terms.

One PPS service is MD customer order release service. This service is designed specifically for MOSP for determining when to release which MD customer orders to which manufacturing plants. The internal mechanism in this service is somewhat complicated because there are multiple manufacturers in the MPSS. All customer orders are pooled and released based on a negotiation mechanism governed by rules agreed by MPSS stakeholders. An MD alliance comprising a project leader and several member enterprises is formed for certain orders by matching their capabilities and capacities with order requirements. Different orders are released to different project leader, and therefore, there are multiple project partnerships between the customers and MD alliance.

Another CPPS service is MD production planning (order release) service. This service is used by all MD enterprises in a MD alliance. Member enterprises input their respective internal production plans and adjustable ranges via a collaborative Gantt chart tools. Taking all the inputs into consideration, the project leader then makes the collaborative production plan of this MD alliance via a central planning tool, aiming at fulfilling current customer order yet causing minimal disturbance to all members' original production plans.

Finally, MD shopfloor scheduling service facilitates each member enterprise making an internal shopfloor scheduling according to the assigned production plan by previous service. The service provides a simple shopfloor modeling 
Fig. 5 Contractor-managed outsourcing services at iMPSS

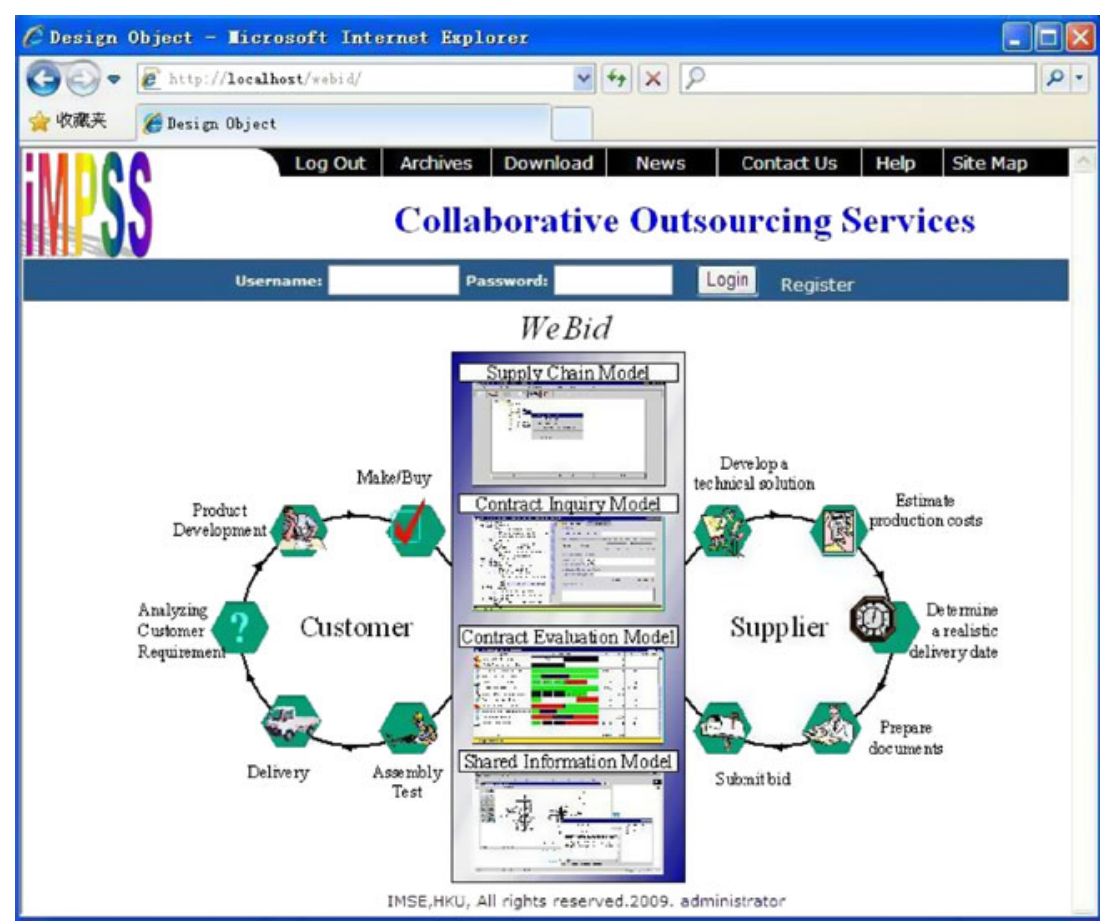

tool which enables an enterprise to describe the machine conditions, such as numbers, capabilities and capacities, as well as availabilities. After shopfloor modeling, an automatic scheduling process is triggered, and a scheduling result is generated.

\section{Concluding discussions}

This paper has discussed extending the PSS concept for creating a new business model for transforming and elevating traditional MD manufacturing industry. The

Fig. 6 Production planning and scheduling (CPPS) services at iMPSS
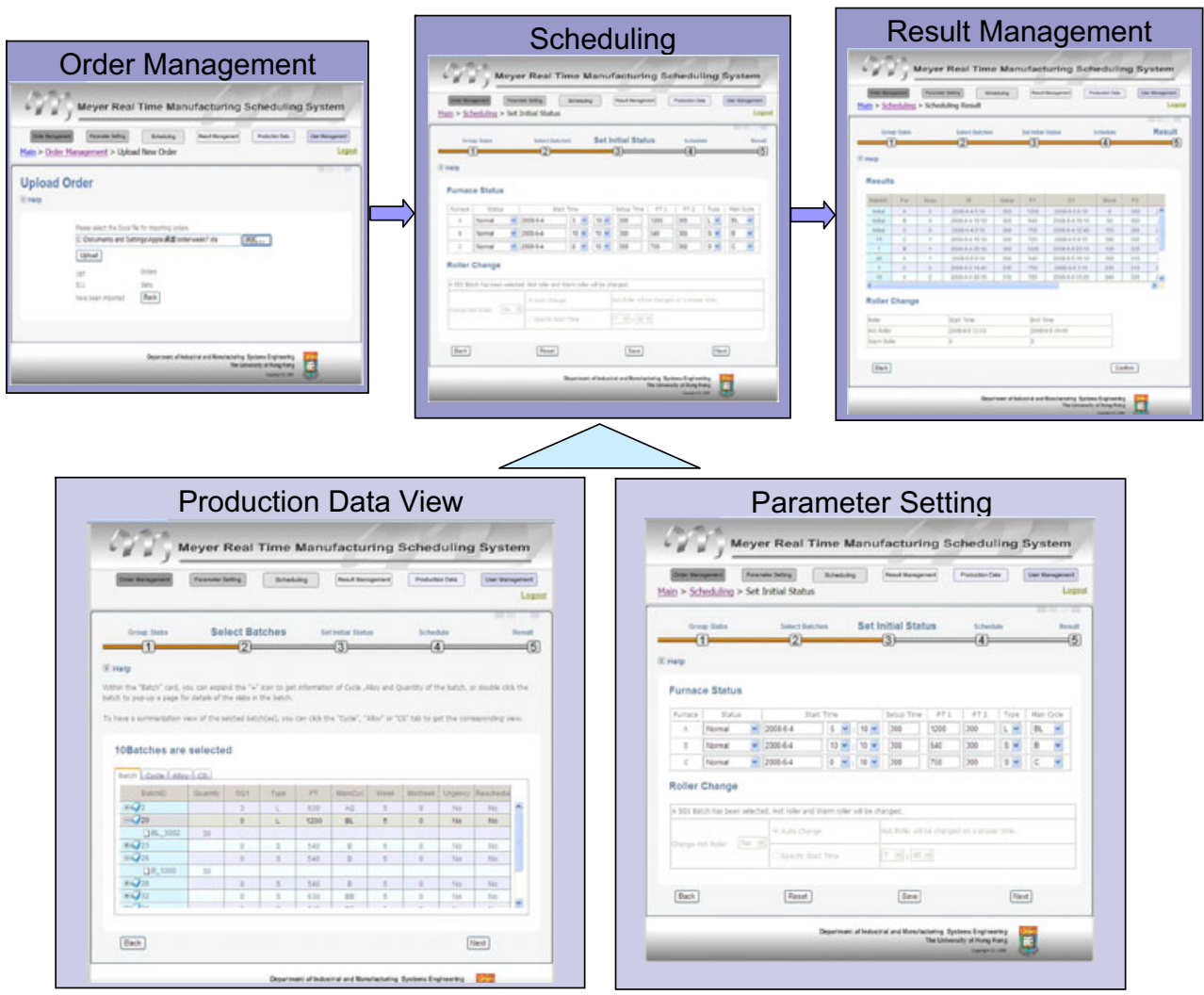
resulting MPSS framework has been based on recent developments within leading MD manufacturers who are service-oriented in the sense that they (1) have more advanced and specialized machining capabilities, (2) are more experienced with IT applications in their businesses, and (3) have more comprehensive customer and supplier bases. These companies are extending their businesses specifically for providing core production-related services to small and medium MD manufacturing enterprises (SME). In order for this new service-oriented business model to become practically operational, this paper has outlined a roadmap for building up an information and collaboration platform for iMPSS, with the regional financial support for a major research and development project. Key MOSs are streamlined and developed based on service-oriented architecture and deployed at iMPSS. Typical services include order/project progress and status tracking services by customers, manufacturers, and outsourcing contractors; outsourcing management services for supply and contract manufacturing; and shopfloor manufacturing execution services. SME MD manufacturers share such application services through an iMPSS portal, instead of investing, installing, and maintaining their own IT solutions. Such shared services would lead to better utilization of specialized capabilities and capacities of participating business partners. Further benefits can be achieved from shared demand and supply pools, both internally and externally, to take advantage of risk pooling effect and scale of economy, through coordinated outsourcing/procurement and customer order-releasing services.

The MPSS concept, technology, and practice are at their infancy stage. Technologically, SOA and SaaS are available for the design and development of iMPSS platform and its services. The key challenge lies in the establishment and streamlining of best practices in relevant shopfloor business processes so that they can be converted into SaaS. An approach to addressing this issue further is to focus on the services that stakeholders believe most worthwhile and gradually scale up the iMPSS platform. Besides, the economy of sharing manufacturing-oriented services requires further studies and pioneering trials. The current economic crisis has forced MD manufacturers to rethink the way of elevating their business models. However, the revenue issue must be resolved for the MPSS concept to be practiced in the MD industry. This is more a business issue than a technological issue. Therefore, it should be dealt with as such. A three-stage approach may be relevant for future deployment. The first stage is to promote the use of iMPSS within a collaborating company and its business units that are related and operated with relative independence between each other. The second stage is to provide iMPSS services to business partners with whom benefits and revenue can be evaluated from their usual business transactions and service consumption levels. The third stage is to open up iMPSS as a general-purpose service portal to MD manufacturing industry through membership schemes in a long run.

Acknowledgements Authors are grateful to HKSAR RGC (HKU 712508E), HKSAR ITF (GHP/042/07LP), Guangdong Province Information Department (06120840B0460124) and HKU Research Committee for financial supports to this research. Authors are also grateful to collaborating companies for the technical support.

Open Access This article is distributed under the terms of the Creative Commons Attribution Noncommercial License which permits any noncommercial use, distribution, and reproduction in any medium, provided the original author(s) and source are credited.

\section{References}

1. Aurich JC, Fuchs C, Wagenknecht C (2006) Life cycle oriented design of technical product-service systems. J Cleaner Prod 14 (17):1480-1494

2. Aurich JC, Fuchs C, Wagenknecht C (2006) Modular design of technical product-service systems. In: Brissaud D et al (eds) Innovation in life cycle engineering and sustainable development. Springer-Verlag, Berlin, pp 303-320

3. Baines TS (2007) State-of-the-art in product-service systems. Proc IMechE 221:1543-1552

4. Besch K (2005) Product-service systems for office furniture: barriers and opportunities on the European market. international institute for industrial environmental economics (IIIEE), Lund University, P.O. Box 196, 22100 Lund, Sweden

5. Britton E (2000) Carsharing 2000: Sustainable transport's missing link. The journal of world transport policy \& practice

6. Cook M, Bhamra T, Lemon M (2006) The transfer and application of product service-systems: from academia to UK manufacturing firms. J Cleaner Prod 14(17):1455-1465

7. Evans S, Partidario PJ, Lambert J (2007) Industrialization as a key element of sustainable product-service solutions. Int J Prod Res 45 (18 \& 19):4225-4246

8. Halliday J (2001) Sustainable growth the dupont way. Harvard business review

9. Huang GQ (2002) Web-based support for collaborative product design review. Int J Comput Ind 48(1):71-88

10. Huang GQ, Mak KL (2000) WeBid: a web-based framework to support early supplier involvement in new product development. Int J Robot Comput Integr Manufacture 16:169-179

11. Huang GQ, Mak KL (2002) Synchronous quality function deployment (QFD) over world wide web. Comput Ind Eng 42 $(2-4): 425-431$

12. Huang GQ, Shi J, Mak KL (2000) Failure mode and effect analysis (FMEA) over the WWW. International Journal of Advanced Manufacturing Technology:603-608

13. Komoto H, Tomiyama T, Nagel M, Silvester S (2005) Life cycle simulation for analyzing product service systems. Environmentally conscious design and inverse manufacturing. Eco design 2005. Fourth International Symposium on

14. Lee J (2003) Smart products and service systems for e-business transformation. Int J Technol Manage 26(1):45-52

15. Luiten H, Knot M, Van TH (2001) Sustainable product-servicesystems: the kathalys method. Environmentally conscious design 
and inverse manufacturing. Proceedings ecodesign 2001: Second International Symposium on

16. Manzini E (1999) Strategic design for sustainability: towards a new mix of products and services. Environmentally conscious design and inverse manufacturing. Proceedings of EcoDesign '99: First International Symposium 1-3, Feb, 1999

17. Manzini E, Vezzoli C (2003) A strategic design approach to develop sustainable product service systems: examples taken from the 'environmentally friendly innovation' Italian prize. J Cleaner Prod 11(8):851-857

18. Manzini E, Vezzoli C, Clark G (2001) Product-service systems. Using an existing concept as a new approach to sustainability. Journal of Design Research 1(2)

19. Meier H, Krug M (2006) Managing the capacity of industrial product-service-systems [J]. PPS Manage 11:48-51

20. Mont O (2002) Clarifying the concept of product service systems. J Cleaner Prod 10(3):237-245

21. Mont $\mathrm{O}$, Lindhqvist $\mathrm{T}$ (2003) The role of public policy in advancement of product service systems. Special paper. J Cleaner Prod 11(8):905-914

22. Mont O, Tukker A (2006) Product-service systems: reviewing achievements and refining the research agenda. J Cleaner Prod 14 (17):1451-1454

23. Morelli N (2002) Product-service systems, a perspective shift for designers: a case study: the design of a telecentre. Des Stud 24 (1):73-99

24. Morelli N (2006) Developing new product service systems (PSS): methodologies and operational tools. J Cleaner Prod 14(17):14951501

25. Oman I (2003) Product service-systems and their impacts on sustainable development - a multi-criteria evaluation for austrian companies. Frontiers
26. Parkersell case study (2004) Methodology for product service systems (MEPSS)

27. Prettenthaler FE, Steininger KW (1999) From ownership to service use lifestyle. The potential of car sharing. Ecol Econ $28: 443-453$

28. Rocchi S (2005) Enhancing sustainable innovation by design, an approach to the co-creation of economic, social and environmental value. $\mathrm{PhD}$ thesis. Rotterdam: Erasmus University

29. Roy R (2000) Sustainable product-service systems. Futures 32(34):289-299

30. Shaheen S, Sperling D, Wagner C (1998) Carsharing in Europe and north America: past, present, and future. Transp Q 52(3): $35-52$

31. Sundin E (2004) Product and process design for successful remanufacturing, linköping studies in science and technology. Dissertation No. 906, dept. of mech. Engineering, linköping university, linköping, Sweden, ISBN 91-85295-73-6

32. Takata S, Kirnura F, van Houten FJAM, Westkamper E, Shpitalni M, Ceglarek D, Lee J (2004) Maintenance: changing role in life cycle management. CIRP Ann Manuf Technol 53 (2):643-655

33. UNEP (2001) The role of PSS in a sustainable society

34. Van den Hoed R (1997) A shift from products to services: an example of washing services. Proceedings 'towards sustainable product design', 2nd international conference, London, July 1997

35. Vergragt PJ, Van der Wel M (1998) Back-casting: an example of sustainable washing. In: Roome N (ed) Sustainable strategies for industry. Island Press, Washington, DC, pp 171-184

36. Williams A (2006) Product service-systems in the automotive industry: a case for micro-factory retailing. J Cleaner Prod $14: 172-184$ 